\title{
Nomenclature notes on some orthoclads (Diptera: Chironomidae)
}

\author{
O. A. SÆTHER \& L. C. FERRINGTON JR.
}

Museum of Zoology, University of Bergen, N-5007 Bergen, Norway and Department of Entomology, University of Minnesota, St.Paul, Minnesota,USA; email: ole.sather@zmb.uib.no

\begin{abstract}
New nomenclatorial acts are proposed for chironomids in anticipation of publication on the Fauna Europaea, a database of the scientific names and distribution of all living multicellular European land and fresh-water animals.

Thienemanniella caspersi Sæther is proposed as a new replacement name for Th. similis Caspers \& Reiss, 1989.

Five new generic combinations are given: Dactylocladius albipennis Goetghebuer, 1921, Orthocladius (Dactylocladius) brevifurcatus Edwards, 1926, and Lindebergia bothnica Tuiskunen, 1984 are transferred to Pseudosmittia Goetghebuer; while Smittia lacunarum Goetghebuer, 1931 and Smittia (Pseudosmittia) terrestris Goetghebuer, 1943 are both transferred to Bryophaenocladius Thienemann.

Twenty-two new synonyms are given: Pseudosmittia amamibifurca Sasa, 1990 is a junior synonym of Pseudosmittia mathildae Albu, 1968; Pseudosmittia antillaria Sæther, 1981 of Pseudosmittia forcipata (Goetghebuer, 1921); Pseudosmittia arenaria flava Strenzke, 1960 of Pseudosmittia arenaria Strenzke, 1960; Smittia avicularia Goetghebuer, 1950 of Pseudosmittia trilobata (Edwards, 1929); Smittia brachyptera Goetghebuer, 1934 of Pseudosmittia conjuncta (Edwards, 1929); Pseudosmittia brevitarsis Brundin, 1947, Pseudosmittia kurobaokasia Sasa \& Okazawa, 1992, Smittia oxoniana Edwards, 1937 not Edwards, 1922, and Pseudosmittia schachti Caspers \& Reiss, 1989 of Pseudosmittia ruttneri Strenzke \& Thienemann, 1942; Spaniotoma (Smittia) curticosta Edwards, 1929 of Pseudosmittia albipennis (Goetghebuer, 1921); Smittia hamata Freeman, 1956 of Pseudosmittia danconai (Marcuzzi, 1947); Pseudosmittia linguata Caspers \& Reiss, 1989 of Pseudosmittia nishiharaensis Sasa \& Hasegawa, 1988; Smittia longitibia Goetghebuer, 1933 and Pseudosmittia mediocarinata Caspers \& Reiss, 1989 of Pseudosmittia nanseni (Kieffer, 1926); Spaniotoma (Smittia) recta Edwards, 1929 and Pseudosmittia togarisea Sasa \& Okazawa, 1992 of Pseudosmittia oxoniana (Edwards, 1922); Spaniotoma (Smittia) scotica Edwards, 1929, Pseudosmittia togasitea Sasa \& Okazawa, 1992, and Pseudosmittia togativea Sasa \& Okazawa, 1992 of Camptocladius stercorarius (De Geer, 1776); Smittia (Orthosmittia) subrecta Goetghebuer, 1943 of Parakiefferiella coronata (Edwards, 1929); Pseudosmittia togadistalis Sasa, Watanabe \& Arakawa, 1992 of Pseudosmittia gracilis (Goetghebuer, 1913); Smittia triappendiculata Goetghebuer 1931 of Pseudosmittia forcipata (Goetghebuer, 1921).
\end{abstract}


Pseudosmittia triplex Strenzke, 1950 is a valid species and not a synonym of $P$. forcipata (Goetghebuer, 1921) as stated in Ashe \& Cranston (1990).

Pseudosmittia virgo montana Strenzke, 1950 is raised to species level as Pseudosmittia montana.

The following names are nomina dubia: Camptocladius flaviventris Kieffer, 1921, Camptocladius hexalobus Kieffer, 1924, Camptocladius longicrus Kieffer, 1921, Pseudosmittia restricta Brundin, 1956, Smittia (Pseudosmittia) tenebrosa Goetghebuer, 1943, Camptocladius trifoliatus Kieffer, 1924, Smittia (Pseudosmittia) vicana Goetghebuer, 1943.

Key words: Nomenclatorial changes, Orthocladiinae, Chironomidae, Thienemanniella, Pseudosmittia

\section{Introduction}

Recently one of us (OAS) was requested to summarise the chironomids in the Fauna Europaea project, a database that will include all terrestrial and aquatic animals of Europe with their distribution in respective countries. Further information is obtainable at http:// www.faunaeur.org. The database will eventually result in a variety of publications for the different groups, but new synonyms and combinations known to us should not be introduced in the database, and we believe it is not desirable to use knowingly wrong names and combinations in the database. We thus find it necessary to publish a list of some of the changes to the nomenclature of the European species, particularly with regard to the genus Pseudosmittia Edwards that we presently are revising. The changes also were proposed in the chironomid newsletter (Sæther, 2002; Sæther \& Ferrington, 2202), but that publication only exists in electronic form without meeting the requirements for nomenclatorial availability as stated in ICZN Article. 8.6.

New name for Thienemanniella similis Caspers \& Reiss, 1989 not Malloch 1915.

Caspers \& Reiss (1989) described a new species, Thienemanniella similis, from Turkey. That name is preoccupied by Thienemanniella similis (Malloch) originally described as Corynoneura similis (Malloch 1915: 413). Hestenes \& Sæther (2000: 113) redescribed the species.

Thienemanniella caspersi Sæther is hereby proposed as a replacement name.

\section{New combinations and synonyms in European Pseudosmittia Goetghebuer and related genera}

While one of us (OAS) was on sabbatical with the other at the University of Kansas, a revision of the genus Pseudosmittia Goetghebuer was begun and a preliminary manuscript describing and re-describing nearly 100 species assignable to the genus was completed. Due to various circumstances, including a change of venue for one of us (LCF) from 
Lawrence, Kansas, to the University of Minnesota in St. Paul, Minnesota, publication has been delayed. The Fauna Europaea project makes it desirable to publish a list of the changes to the nomenclature of the European species belonging to Pseudosmittia and related genera. We have examined the type material in most relevant museums, but a few remain to be investigated. Here we list only new combinations, new synonyms, new nomina dubia or other changes relative to the catalogue by Ashe \& Cranston (1990).

The following abbreviations for collections are used:

BMNH:The Natural History Museum (British Museum, Natural History), London, England

IRSN: Institute Royal de Science Naturelles de Belgique, Bruxelles, Belgium.

NMS: Natur-Museum Senckenberg, Frankfurt Am Main, Germany.

NSMT: National Science Museum, Shinjuku Branch, Tokyo, Japan.

ZMB: Museum of Zoology, University of Bergen, Norway.

ZMH: Zoological Museum, University of Helsinki, Finland.

ZMO: Zoological Museum. University of Oslo, Norway.

ZSM: Zoologisches Staatssammlung, Munich, Germany.

\section{New generic combinations}

Dactylocladius albipennis Goetghebuer, 1921: 85 (= Pseudosmittia albipennis (Goetghebuer), comb. n.). Holotype male in IRSN.

Orthocladius (Dactylocladius) brevifurcatus Edwards, 1926: 781 (= Pseudosmittia brevifurcata (Edwards), comb. n.). Types in BMNH.

Lindebergia bothnica Tuiskunen, 1984: 121 (= Pseudosmittia bothnica (Tuiskunen), comb. n.). Holotype male in ZMH.

Smittia lacunarum Goetghebuer, 1931: 217 (= Bryophaenocladius lacunarum (Goetghebuer), comb. n.). Holotype male in IRSN.

Smittia (Pseudosmittia) terrestris Goetghebuer, 1943: 109 (= Bryophaenocladius terrestris (Goetghebuer), comb. n.). Holotype female in IRSN.

\section{New synonyms}

Pseudosmittia amamibifurca Sasa, 1990: 132 (=Pseudosmittia mathildae Albu, 1968, syn. n.). Holotype male in NSMT.

Pseudosmittia antillaria Sæther, 1981: 29 (= Pseudosmittia forcipata (Goetghebuer, 1921), syn. n.). Holotype male in ZMB.

Pseudosmittia arenaria flava Strenzke, 1960: 419 (= Pseudosmittia arenaria Strenzke, 1960, syn. n.). Holotype female in NMS. 
Smittia avicularia Goetghebuer, 1950: 13 (= Pseudosmittia trilobata (Edwards, 1929), syn. n.). Holotype male in IRSN.

Smittia brachyptera Goetghebuer, 1934: 389 (= Pseudosmittia conjuncta (Edwards, 1929), syn. n.). Holotype male in IRSN.

Pseudosmittia brevitarsis Brundin, 1947: 40 (= Pseudosmittia ruttneri Strenzke \& Thienemann, 1942, syn. n.). The type could not be located.

Spaniotoma (Smittia) curticosta Edwards, 1929: 364 (= Pseudosmittia albipennis (Goetghebuer, 1921), syn. n.). Holotype male in BMNH.

Smittia hamata Freeman, 1956: 355 (= Pseudosmittia danconai (Marcuzzi, 1947), syn. n.). Holotype male in NMS. Paratypes in BMNH also examined.

Pseudosmittia linguata Caspers \& Reiss, 1989: 128 (= Pseudosmittia nishiharaensis Sasa \& Hasegawa, 1988, syn. n.). Holotype male in ZSM.

Pseudosmittia kurobaokasia Sasa \& Okazawa 1992a: 57 (= Pseudosmittia ruttneri Strenzke \& Thienemann, 1942, syn. n.). Holotype male in NSMT.

Smittia longitibia Goetghebuer, 1933: 29 (= Pseudosmittia nanseni (Kieffer, 1926), syn. n.). Holotype male in ZMO.

Pseudosmittia mediocarinata Caspers \& Reiss, 1989: 132 (= Pseudosmittia nanseni (Kieffer, 1926), syn. n.). Holotype male in ZSM.

Smittia oxoniana Edwards, 1937: 146, not Edwards, 1922: 204 (= Pseudosmittia ruttneri Strenzke \& Thienemann, 1942, syn. n.). Two males, 1 female, det. F. Edwards (NMS). Spaniotoma (Smittia) recta Edwards, 1929: 362 (= Pseudosmittia oxoniana (Edwards, 1922, syn. n.). Holotype male in BMNH.

Pseudosmittia schachti Caspers \& Reiss, 1989: 130 (= Pseudosmittia ruttneri Strenzke \& Thienemann, 1942, syn. n.). Holotype male in ZSM. Paratype male misidentified $P$. oxoniana (Edwards).

Spaniotoma (Smittia) scotica Edwards, 1929: 363 (= Camptocladius stercorarius (De Geer, 1776), syn. n.). Holotype female in BMNH.

Smittia (Orthosmittia) subrecta Goetghebuer, 1943: 112 (= Parakiefferiella coronata (Edwards, 1929), syn. n.). Types in IRSN.

Pseudosmittia togadistalis Sasa, Watanabe \& Arakawa, 1992: 233 (= Pseudosmittia gracilis (Goetghebuer, 1913), syn. n.). Holotype male in NSMT.

Pseudosmittia togarisea Sasa \& Okazawa, 1992b: 160 (= Pseudosmittia oxoniana (Edwards, 1922), syn. n.). Holotype male in NSMT.

Pseudosmittia togasitea Sasa \& Okazawa, 1992b: 161 (= Camptocladius stercorarius (De Geer, 1776), syn. n.). Holotype male in NSMT.

Pseudosmittia togativea Sasa \& Okazawa, 1992b: 162 (= Camptocladius stercorarius (De Geer, 1776), syn. n.). Holotype male in NSMT.

Smittia triappendiculata Goetghebuer, 1931: 216 (= Pseudosmittia forcipata (Goetghebuer, 1921), syn. n.). Holotype male in IRSN. 
Pseudosmittia triplex Strenzke, 1950: 301. Valid species and not a synonym of P. forcipata (Goetghebuer, 1921) as stated in Ashe \& Cranston (1990). Holotype male in NMS.

\section{New status}

Pseudosmittia virgo montana Strenzke, 1950: 303 (= Pseudosmittia montana Strenzke, 1950, stat. n.). Holotype male with pupal exuviae in NMS.

\section{Nomina dubia}

Camptocladius flaviventris Kieffer, 1921a: 289, nomen dubium. The type could not be located.

Camptocladius hexalobus Kieffer, 1924: 395 (= Pseudosmittia hexalobus Kieffer, nomen dubium). Type lost. A likely senior synonym of either P. trilobata or P. obtusa.

Camptocladius longicrus Kieffer, 1921b: 100, nomen dubium. Type lost. A pupal exuviae from NMS is marked type, but collected in 1941 and thus wrongly marked.

Pseudosmittia restricta Brundin, 1956: 170, nomen dubium. The type could not be found. The species cannot belong in Pseudosmittia if the description is correct; a distinct scutal hump is present and the genitalia differ from all other known species.

Smittia (Pseudosmittia) tenebrosa Goetghebuer, 1943: 109 (= Pseudosmittia tenebrosa (Goetghebuer), nomen dubium). Holotype male in IRSN. Mounted between two plastic strips on a pin and ruined in attempt of remounting. Probably a synonym of $P$. simplex Strenzke \& Thienemann.

Camptocladius trifoliatus Kieffer, 1924: 73, nomen dubium. The type could not be located. Smittia (Pseudosmittia) vicana Goetghebuer, 1943: 110 (= Pseudosmittia vicana (Goetghebuer), nomen dubium). The female holotype supposedly in IRSN could not be found.

\section{References}

Albu, P. (1968) Pseudosmittia mathildae sp. n. (Diptera, Chironomidae). Annales Zoologici Fennici, 5, 4-5.

Ashe, P. \& Cranston, P.S. (1990) Family Chironomidae. In: Sóos, Á. \& Papp, L. (Eds.) Catalogue of Palaearctic Diptera. Vol. 2 Psychodidae - Chironomidae. Akadémia Kiadó, Budapest, pp. $113-355$.

Brundin, L. (1947) Zur Kenntnis der schwedischen Chironomiden. Arkiv för Zoologi, 39 A, 1-95. 
Brundin, L. (1956) Zur Systematik der Orthocladiinae (Dipt., Chironomidae). Institute of Freshwater Research, Drottningholm, Report, 37, 5-185.

Caspers, N. \& Reiss, F. (1989) Die Chironomidae der Türkei. Teil I: Podonominae, Diamesinae, Prodiamesinae, Orthocladiinae (Diptera, Nematocera, Chironomidae). Entomofauna, 10, 105160.

Edwards, F.W. (1922) Results of the Oxford University Expedition to Spitsbergen, 1921. Annals and Magazine of Natural History, (9) 10, 193-215.

Edwards, F.W. (1926) On marine Chironomidae (Diptera) with descriptions of a new genus and four new species from Samoa. Proceedings of the Zoological Society of London, 1926, 779806.

Edwards, F.W. (1929) British non-biting midges (Diptera, Chironomidae). Transactions of the Entomological Society of London, 77, 279-430.

Edwards, F.W. (1937) Chironomidae (Diptera) collected by Prof. Aug. Thienemann in Swedish Lapland. Annals and Magazine of Natural History, (10) 20, 140-148.

Goetghebuer, M. (1921) Chironomides de Belgique et spécialement de la zone des Flandres. Mémoires du Musée Royal d'Histoire Naturelle de Belgique, 8, 1-211.

Goetghebuer, M. (1931) Ceratopogonidae et Chironomidae nouveaux d'Europe. Bulletin \& Annales de la Société Royale d'Entomologique de Belgique, 71, 211-218.

Goetghebuer, M. (1933) Chironomides du Groenland oriental, du Svalbard et de la terre de Francois Joseph. Skrifter om Svalbard og Ishavet, 53, 19-31.

Goetghebuer, M. (1934) Note sur un nouveau Chironomide brachyptère. Bulletin \& Annales de la Société Royale d'Entomologique de Belgique, 74, 388-390.

Goetghebuer, M. (1942) 13g. Tendipedidae (Chironomidae). f) Subfamilie Orthocladiinae. A. Die Imagines (part). Die Fliegen der Palaearktischen Region, 3(1), 25-64.

Goetghebuer, M. (1950) Ceratopogonidae et Chironomidae nouveaux ou peu connus d'Europe (Treizième note). Bulletin de la Institute Royal des Sciences Naturelles de Belgique, 25(14), 18.

Hestenes, T.C. \& Sæther, O.A. (2000) Three new Nearctic Thienemanniella Kieffer species with a review of the Nearctic species. In: Hoffrichter, O. (ed.), Late $20^{\text {th }}$ century research on Chironomidae: an anthology from the $13^{\text {th }}$ international symposium on Chironomidae. Shaker Verlag, Aachen, pp. 103-127.

Kieffer, J.J. (1921a) Chironomides de Courlande. Annales de la Société Scientifique de Bruxelles, 40, 275-298.

Kieffer, J.J. (1921b) Chironomides nouveaux ou peu connus de la région paléarctique. Bulletin de la Société d'Histoire Naturelle de Metz, 29, 51-109.

Kieffer, J.J. (1924) Quelques chironomides nouveaux et remarquables du Nord de l'Europe. Annales de la Société Scientifique de Bruxelles, 43, 390-397.

Kieffer, J.J. (1926) Chironomiden der 2. Fram-Expedition (1898-1902). Norsk Entomologisk Tidsskrift, 2[1925], 78-89.

Malloch, J.R. (1915) The Chironomidae, or midges, of Illinois, with particular reference to the species occurring in the Illinois River. Bulletin of the Illinois State Laboratory of Natural History, $10,275-543$.

Marcuzzi, G. (1947) Descrizione di tre nuove specie di Smittia della Laguna di Venezia. Bolletino della Società Entomologica Italiana, 77, 9-13.

Pinder, L. C.V. (1978) A key to adult males of British Chironomidae. Part 1. The key; part 2. Illustrations of the hypopygia. Freshwater Biological Association, Scientific Publication 37, 169 pp.; 189 figs.

Sæther, O.A. (1981) Orthocladiinae (Diptera: Chironomidae) from the British West Indies, with descriptions of Antillocladius n. gen., Lipurometriocnemus n. gen. Compterosmittia n. gen. and Diplosmittia n. gen. Entomologica scandinavica, Supplement 16, 1-46. 
Sæther, O.A. (2002) New name for Thienemanniella similis Caspers \& Reiss, 1989 not Malloch, 1915. Chironomus, 15, 34.

Sæther, O.A. \& Ferrington, L.C. Jr. (2002) New combinations and synonyms in European Pseudosmittia Goetghebuer and related genera (Diptera: Chironomidae). Chironomus, 15, 14-16.

Sasa, M. (1984) Studies on chironomid midges in lakes of the Nikko National Park. Pt. II. Taxonomical and morphological studies on the chironomid species collected from lakes in the Nikko National Park. Research Report from the National Institute of Environmental Studies, Japan, 70, 16-215.

Sasa, M. (1990) Studies on the chironomid midges (Diptera, Chironomidae) of the Nansei Islands, Southern Japan. Japanese Journal of Experimental Medicine, 60, 111-165.

Sasa, M. \& Hasegawa, H. (1988) Additional records of the chironomid midges from the Ryukyu Islands, southern Japan (Diptera, Chironomidae). Japanese Journal of Sanitary Zoology, 39, 229-256.

Sasa, M. \& Okazawa, T. (1992 a) Studies on the chironomid midges (yusurika) of Kurobe River. Research Report from Toyama Prefectural Environmental Pollution Research Centre, 1992, 40-91.

Sasa, M. \& Okazawa, T. (1992b) Studies on the chironomid meidges (yusurika) of Toga-Mura, Toyama. Part 2. The subfamily Orthocladiinae. Research Report from Toyama Prefectural Environmental Pollution Research Centre, 1992, 92-204.

Sasa, M., Watanabe M. \& Arakawa, R. (1992) Additional records of Chironomidae from TogaMura, 1992. Research Report from Toyama Prefectural Environmental Pollution Research Centre, 1992, 231-246.

Strenzke, K. (1950) Systematik, Morphologie und Ökologie der terrestrischen Chironomiden. Archiv für Hydrobiologie, Supplement, 18, 207-414.

Strenzke, K. \& Thienemann, A. (1942) Zwei neue Pseudosmittia-Arten (Diptera, Chironomidae) aus dem Gebiete der Lunzer Seen. International Revue der Gesamten Hydrobiologie und Hydrographie, 42, 356-387.

Tuiskunen, J. (1984) Lindebergia bothnica, gen. n., sp. n. (Diptera, Chironomidae) from Finland. Annales Entomologici Fennicae, 50, 121-122. 